\title{
Life cycle assessment of flame retardants in an electronics application
}

\author{
Niels Jonkers ${ }^{1}$ • Hildo Krop ${ }^{1}$ - Harry van Ewijk ${ }^{1}$ • Pim E. G. Leonards ${ }^{2}$
}

Received: 30 July 2015 / Accepted: 4 November 2015 / Published online: 17 November 2015

(C) The Author(s) 2015. This article is published with open access at Springerlink.com

\begin{abstract}
Purpose Flame retardants are added to plastics and textiles to save lives. However, certain brominated flame retardants (BFRs) form an environmental hazard and should be replaced by less harmful alternatives. In the recently completed European research project ENFIRO, we examined which alternatives are most suitable from a technical and environmental perspective. This study describes the LCA comparison of BFRs and halogen-free flame retardants (HFFRs) in an electronics product, in order to compare their environmental impacts over the whole life cycle and identify where in the life cycle the main impacts occur.

Methods This cradle to grave LCA used the complete life cycle of a laptop computer as the functional unit. Specific attention was paid to often neglected aspects, including emissions of flame retardants in all life cycle phases, emissions during accidental fire and improper waste treatment. New characterization factors for toxicity of flame retardants were calculated using USES-LCA2 and included in the impact assessment.

Results and discussion The largest differences in impact were found to occur in the waste phase due to an increased dioxin emission formed out of BFRs during improper waste treat-
\end{abstract}

Responsible editor: Ivan Muñoz

Electronic supplementary material The online version of this article (doi:10.1007/s11367-015-0999-z) contains supplementary material, which is available to authorized users.

Niels Jonkers

njonkers@ivam.uva.nl

1 IVAM, University of Amsterdam, Plantage Muidergracht 24, 1018 TV Amsterdam, The Netherlands

2 Institute for Environmental Studies (IVM), VU University, de Boelelaan 1087, 1081 HV Amsterdam, The Netherlands ment. Minor human toxicity and ecotoxicity impacts of FRs are present due to volatilization in the use phase. FR emissions during accidental fire vary with the FR's mode of action (active in the gaseous or solid phase). The BFR scenario has a higher impact than the HFFR scenario due to a higher rate of smoke formation and a higher terrestrial ecotoxicity score. In most phases of the life cycle of FRs, fossil energy use related impact categories dominate the LCA score, i.e. climate change, fossil depletion, and particulate matter formation. Over the full life cycle, the BFR scenario has a slightly higher environmental impact than the HFFR scenario, mainly through the contribution of human toxicity in the waste phase. Conclusions The study shows that for improvements of the life cycle environmental performance of FRs, the waste treatment phase is critical. Export and improper treatment of WEEE have the highest impact of all waste treatment options for both the BFR and HFFR scenarios, and efforts should be intensified to reduce the amount of WEEE ending up in this scenario. The study further shows that processes which are often ignored in LCA can give relevant insights into the environmental performance of a product. It is therefore recommended to broaden the scope and system boundaries of future LCA studies to include unofficial scenario options (specifically in the end-of-life phase) to provide a more complete description of the full environmental impact of a product's life cycle and thereby contribute to relevant discussions in society and policy.

Keywords Electronics $\cdot$ Flame retardants $\cdot$ Laptop $\cdot$ Plastics additives $\cdot$ Life cycle assessment (LCA) $\cdot$ WEEE

\section{Introduction}

Flame retardants are applied in a large range of consumer products to improve fire safety. Global production volumes of flame 
retardants are estimated at 2.6 Mton in 2016 (Freedonia 2013). Many flame retardants function by preventing or absorbing radicals formed during a combustion process. Consequently, these substances are often designed to be stable up to high temperatures and are therefore not easily degradable. These properties also mean that these substances are persistent in the environment. In addition, some flame retardants exhibit high ecotoxicity and therefore pose a hazard to the environment. In particular, certain brominated flame retardants (BFRs, specifically polybrominated diphenyl ethers) are a cause of concern and should therefore be substituted by less harmful ones (Chen and Hale 2010; D'Silva et al. 2004; De Wit 2002).

In recent years, a number of alternative flame retardants (halogen-free flame retardants, HFFRs) have been developed as possible substitution products for BFRs. Substitution of flame retardants (and plastics additives in general) is a complex task. A number of requirements must be met on both fire safety, compatibility with the plastic, mechanical, physical and electrical properties, health and environmental properties and commercial viability (Lavoie et al. 2010).

The knowledge on the functional, environmental and toxicological properties of HFFRs is limited compared to the BFRs (Shaw et al. 2010; Waaijers et al. 2013). The recently completed EU-funded research project 'Life Cycle Assessment of Environment-Compatible Flame Retardants: Prototypical Case Study' (ENFIRO) aimed to establish which alternatives are most suitable, from both a technical and environmental point of view (www.enfiro.eu). In this project, environmental scientists, chemists, toxicologists, material scientists and fire safety researchers joined forces to evaluate all relevant aspects of alternative flame retardants, in order to determine which alternatives are most viable.

One of the studies within this project was an environmental life cycle assessment (LCA), which compared the environmental impacts over the full life cycle for selected BFRs and HFFRs. This study made use of both literature data and new experimental data from the ENFIRO project on properties and environmental behaviour of FRs. The product system considered was a combination of several flame-retarded polymers incorporated in an electronics product. A laptop computer was selected as case study.

Most LCA literature in which polymers are studied and does not consider polymer additives such as flame retardants (or stabilizers or plasticizers). Some studies exist which do take into account the presence of flame retardants in, e.g. TVs, notably some efforts in which the occurrence of fires is incorporated into the environmental impact calculations (Andersson et al. 2003, 2004; De Poortere et al. 2000; Hamzia et al. 2008; Simonson et al. 2002). Some additional studies have been found on aspects of the life cycle of printed wiring boards (PWBs), which are an important application of flame retardants (Alaee et al. 2003; Andrae et al. 2005; Iji and Yokoyama 1997; Scharnhorst et al. 2005).
Some literature on LCA studies of electronics is available (Andrae et al. 2000, 2004; Andrae and Vaija 2014; Ciroth and Franze 2011; Dodbiba et al. 2008; Duan et al. 2009; Elduque et al. 2014; Gunnar Bergendahl et al. 2005; Hischier 2015; Hischier and Baudin 2010; Yung et al. 2009). Results vary considerably, depending on system boundaries, data sources and assumptions. A common view in the LCA community is that 'any product with a plug' will have its main environmental impact in the use phase. Although this is probably true for ovens and washing machines, it does not hold (anymore) for all electronics (Andrae and Andersen 2010). In some studies, environmental impact scores for the manufacturing phase and use phase are comparable and sometimes the manufacturing phase scores higher. The reported scores for the waste phase depend very much on the scenario: dumping on a landfill can have a score similar to the manufacturing and use phase, while the score for proper WEEE treatment scores lower or even negative (environmental benefit due to recycling). LCA studies on the improper treatment of WEEE in developing countries are extremely rare (Andrae et al. 2008).

The environmental impact of FRs is normally not discussed in LCA studies on electronics. Sometimes, the plastics used in electronics are considered to be simple polymers, ignoring any additives that may be used (Ciroth and Franze 2011; Dodbiba et al. 2008). In those studies, the environmental impact of the metals used in electronics by far outweighs the impact of the plastics used.

The current comparative attributional LCA study intends to compile the knowledge on the environmental effects of specific brominated and halogen-free flame retardants over their whole life cycle and to demonstrate which of the alternatives have the lowest overall environmental impact. In addition, the study shows in which stages of the life cycle the highest environmental gain may be achieved by future improvements. Processes such as accidental fire, volatilization of FRs in the use phase, and improper waste disposal are included in the study. These aspects are often ignored in LCA, but much discussed in society, and we believe that including them, this study can be a useful contribution to the debate on FR substitution.

\section{Methods}

\subsection{Functional unit and system boundaries}

The product system considered is a flame retardant system incorporated in a commercial product, i.e. a laptop computer. A comparison was made between a brominated flame retardant system and a non-brominated one. The functional unit is defined as: 'the complete life cycle of a laptop containing flame retarded polymers, with a lifetime of 4 years'. Abbreviations of the FRs and polymers studied are given in Table 1. 
Table 1 Abbreviations used in this study

\begin{tabular}{ll}
\hline ABS & Acrylonitrile butadiene styrene terpolymer \\
Alpi & Aluminium diethylphosphonate \\
ATH & Aluminium trihydroxide \\
ATO & Antimony trioxide \\
BDP & Bisphenol-A bis(diphenylphosphate) \\
BFR & Brominated flame retardant \\
BPS & Brominated polystyrene \\
DecaBDE & Decabromo diphenylether \\
DOPO & 9,10-Dihydro-9-oxa-10-phosphaphenanthrene-10-oxide \\
EPR & Epoxy resin \\
EPS & (expanded) Polystyrene foam \\
EVA & Ethylene vinyl acetate \\
FR & Flame retardant \\
HFFR & Halogen free flame retardant \\
HIPS & High-impact polystyrene \\
MPP & Melamine polyphosphate \\
MSWI & Municipal solid waste incineration \\
PA66 & Polyamide (Nylon 6,6) \\
PAHs & Polycyclic aromatic hydrocarbons \\
PC & Polycarbonate \\
PPE & Polyphenylene ether \\
PWB & Printed wiring board \\
RDP & Resorcinol bis(diphenylphosphate) \\
TBBPA & Tetrabromobisphenol A \\
TEQ & Toxic equivalent \\
VOCs & Volatile organic compounds \\
WEEE & Waste electrical and electronic equipment \\
ZHS & Zinc hydroxystannate \\
ZS & Zinc stannate \\
\hline &
\end{tabular}

Figure 1 shows the life cycle for an FR that is incorporated as additive into a polymer, which is then used in an electronics product. All relevant processes in the life cycle are included (cradle-to-grave). This includes all 'standard' production, use and disposal processes, but also emissions during use, accidental fire, proper electronics disposal according to the European WEEE Directive and substandard waste disposal of electronic products. Emission of FRs to the environment may occur in several life cycle phases and are specifically included as well.

The system boundaries of this study were set at end-of-life recycling, which means that the potential environmental loads and benefits of recycling are not included.

\subsection{Inventory data}

Foreground data has been obtained from stakeholders from industry, NGOs and academia via stakeholder meetings in the ENFIRO project. Other foreground data was produced by the project partners, in particular data on the

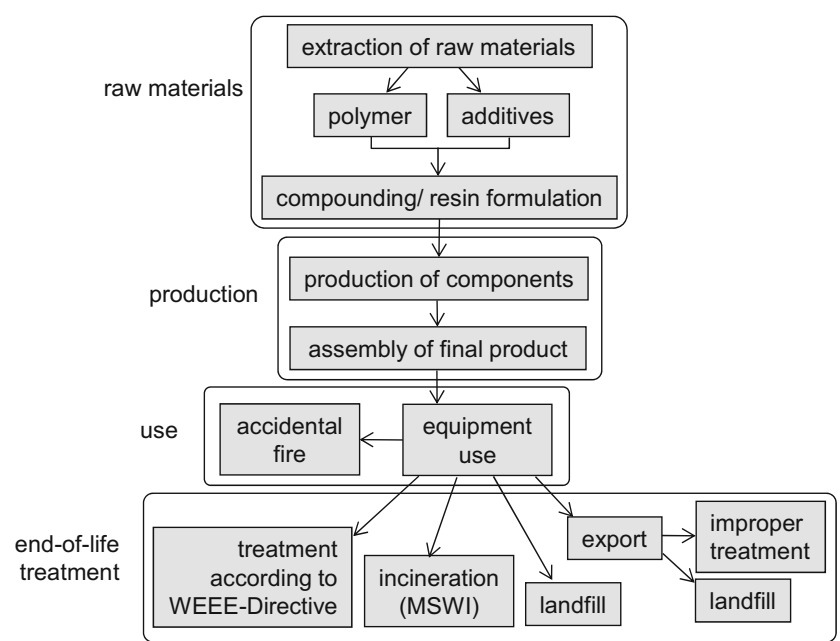

Fig. 1 The life cycle of flame retarded polymers in an electronics application

environmental fate of the FRs. These data were used in the calculations of ecotoxicological and human toxicological characterization factors of FRs. Studies in the ENFIRO project on the functional and fire safety properties of the FR-polymer combinations served to select combinations which comply with the requirements for electronic equipment and determine which emissions can be expected during accidental fire. Data from scientific literature or publicly available patents were used in cases where actual data from stakeholders could not be obtained. For background data, the LCA-database Ecoinvent 2.0 was used.

Starting point for the derivation of emission factors of flame retardants in different phases of the life cycle are the EU Technical Guidance Document on the risk assessment of chemicals (European Commission 2003) and the OECD document on emission scenarios for plastics additives (OECD 2004). In some cases, data reported by industry could be used for the calculation of emission factors, i.e. flame retardants which have been subjected to an EU risk assessment, and flame retardants which are part of the VECAP initiative (VECAP 2011; European Commission 2002, 2007, 2008a). The FR emission factors used in this study are listed in Table 2.

\subsubsection{Production of flame retardants}

Table 3 lists the HFFRs and BFRs modelled in this study. Details on the production of FRs were in some cases provided by main European FR producers. When no specific industry data was received, an inventory was made using LCA literature, patent descriptions and Ullman's Encyclopedia of Industrial Chemistry. Details on flame retardant production can be found in the Electronic Supplementary Material. 
Table 2 Emission factors for flame retardants in different phases of the life cycle, as used in this study

\begin{tabular}{|c|c|c|}
\hline $\begin{array}{l}\text { Life cycle phase, } \\
\text { compound }\end{array}$ & Compartment & $\begin{array}{l}\text { Emission } \\
\text { factor }\end{array}$ \\
\hline \multicolumn{3}{|l|}{ Production of FR } \\
\hline \multirow[t]{3}{*}{ decaBDE ${ }^{\mathrm{a}}$} & Air & $1.1 \mathrm{E}-5$ \\
\hline & Water & $1.8 \mathrm{E}-5$ \\
\hline & Land & $3.1 \mathrm{E}-5$ \\
\hline \multirow[t]{3}{*}{ TBBPA $^{\mathrm{a}}$} & Air & $1.0 \mathrm{E}-6$ \\
\hline & Water & $2.0 \mathrm{E}-7$ \\
\hline & Land & 0 \\
\hline \multirow[t]{3}{*}{$\mathrm{ATO}^{\mathrm{b}}$} & Air & 7.6E-5 \\
\hline & Surface water & $2.8 \mathrm{E}-7$ \\
\hline & Wastewater & $4.7 \mathrm{E}-8$ \\
\hline Other FRs ${ }^{c}$ & Wastewater & 0.003 \\
\hline \multicolumn{3}{|l|}{ Industrial processes } \\
\hline \multirow[t]{2}{*}{ decaBDE ${ }^{\mathrm{d}}$} & Air & $1.0 \mathrm{E}-4$ \\
\hline & Water & $5.0 \mathrm{E}-4$ \\
\hline \multirow[t]{2}{*}{ TBBPA $^{\mathrm{e}}$} & Air & $1.00 \mathrm{E}-5$ \\
\hline & Water & $1.01 \mathrm{E}-5$ \\
\hline \multirow[t]{3}{*}{$\mathrm{ATO}^{\mathrm{b}}$} & Air & $1.63 \mathrm{E}-6$ \\
\hline & Wastewater & $3.5 \mathrm{E}-4$ \\
\hline & Solid waste & $1.6 \mathrm{E}-2$ \\
\hline \multirow[t]{2}{*}{ Inorganic FRs ${ }^{\mathrm{f}}$} & Water & $2.0 \mathrm{E}-4$ \\
\hline & Air & 0 \\
\hline \multirow[t]{2}{*}{ Low volatility organic $\mathrm{FRs}^{\mathrm{f}}$} & Water & $1.2 \mathrm{E}-4$ \\
\hline & Air & $2.0 \mathrm{E}-5$ \\
\hline \multirow[t]{2}{*}{ Medium volatility organic FRs ${ }^{\mathrm{f}}$} & Water & $2.0 \mathrm{E}-4$ \\
\hline & Air & $1.0 \mathrm{E}-4$ \\
\hline \multicolumn{3}{|l|}{ Use phase } \\
\hline $\operatorname{decaBDE}^{\mathrm{d}}$ & Air & 0.0019 \\
\hline $\mathrm{ATO}^{\mathrm{b}}$ & Wastewater & $1.0 \mathrm{E}-4$ \\
\hline \multirow[t]{2}{*}{ Inorganic FRs ${ }^{\mathrm{f}}$} & Water & $1.0 \mathrm{E}-4$ \\
\hline & Air & 0 \\
\hline \multirow[t]{2}{*}{ Low volatility organic FRs ${ }^{\mathrm{f}}$} & Water & $5.0 \mathrm{E}-4$ \\
\hline & Air & $5.0 \mathrm{E}-4$ \\
\hline Reactive FRs & & 0 \\
\hline \multicolumn{3}{|l|}{ Accidental fire } \\
\hline Organic FRs ${ }^{g}$ & Air & $3.0 \mathrm{E}-7$ \\
\hline $\mathrm{ATO}^{\mathrm{g}}$ & Air & 0.84 \\
\hline Other inorganic FRs ${ }^{\mathrm{h}}$ & Air & 0.084 \\
\hline \multicolumn{3}{|l|}{$\begin{array}{l}\text { Waste phase, treatment } \\
\text { according to WEEE Directive }\end{array}$} \\
\hline All FRs & Air & 0.001 \\
\hline \multicolumn{3}{|l|}{ Waste phase, landfill } \\
\hline All FRs ${ }^{\mathrm{i}}$ & Surface water & $\begin{array}{l}\text { Between } \\
3.8 \mathrm{E}-8 \text { and } 1\end{array}$ \\
\hline \multicolumn{3}{|l|}{ Waste phase, incineration } \\
\hline \multirow[t]{2}{*}{$\mathrm{ATO}^{\mathrm{b}}$} & Air & 0.001 \\
\hline & Surface water & 0.003 \\
\hline Inorganic FRs & Air & 0.001 \\
\hline
\end{tabular}

Table 2 (continued)

\begin{tabular}{lll}
\hline $\begin{array}{l}\text { Life cycle phase, } \\
\text { compound }\end{array}$ & Compartment & $\begin{array}{l}\text { Emission } \\
\text { factor }\end{array}$ \\
\hline & Surface water & 0.003 \\
Organic FRs & Air & $3.0 \mathrm{E}-8$ \\
Waste phase, substandard treatment & & \\
Organic FRs & Air & $3.0 \mathrm{E}-7$ \\
ATO $^{\mathrm{j}}$ & Air & 0.005 \\
ZHS $^{\mathrm{j}}$ & Air & 0.037 \\
$\mathrm{ATH}^{\mathrm{j}}$ & Air & 0.037 \\
\hline
\end{tabular}

${ }^{a} \operatorname{VECAP}(2011)$

${ }^{\mathrm{b}}$ European Commission (2008a)

${ }^{\mathrm{c}}$ European Commission (2003)

${ }^{\mathrm{d}}$ European Commission (2002)

${ }^{\mathrm{e}}$ European Commission (2007)

${ }^{\mathrm{f}} \mathrm{OECD}$ (2004)

${ }^{\mathrm{g}}$ Simonson et al. (2000)

${ }^{\mathrm{h}}$ Cusack (2008)

${ }^{\mathrm{i}}$ Laboratory data ENFIRO project (see Electronic Supplementary Material)

${ }^{\mathrm{j}}$ Gullett et al. (2007)

\subsubsection{Production of a laptop}

With sales of around 400 million worldwide in 2015, laptops are produced in a wide range of designs and materials (Andrae and Edler 2015). The extent to which FRs are used in laptops can vary as well. It was assumed that all main polymer materials are flame retarded, including PWBs, connectors and switches, cables and casing. Starting point for the exact laptop composition was the Ecoinvent process 'Laptop computer, at plant'. Several studies are available reporting detailed laptop compositions and the presence of FRs in laptops (Brigden et al. 2007; ChemSec 2010; Deng et al. 2011; Destaillats et al. 2008; EFRA 2010; IVF 2007). The averages of the weight percentages of different polymers were used for our LCA scenarios, as shown in Table 3. The FR loadings are based on fire safety tests performed within the ENFIRO project and apply to polymer materials passing a V0 test.

In the Ecoinvent laptop process sheet (as well as in underlying process sheets on laptop components), the amounts of polymers were set to 0 . The polymers from Table 3 were added to the LCA scenario as separate processes. In this way, the environmental impact of the FR-polymers can be specifically shown, and double-counting of the polymers is avoided.

\subsubsection{The use phase}

Energy consumption of the laptop Electricity consumption of different laptop modes has been taken from the Ecoinvent database. The total electricity consumption over the lifetime of 
Table 3 Average amounts of polymer used in the laptop, and loading rates (weight-\%) of the HFFRs and BFRs in the polymers

\begin{tabular}{|c|c|c|c|c|c|c|}
\hline \multirow[t]{2}{*}{ Polymer } & \multirow[t]{2}{*}{ Amount in laptop $(\mathrm{kg})$} & \multicolumn{2}{|l|}{ BFR scenario } & \multicolumn{2}{|l|}{ HFFR scenario } & \multirow[t]{2}{*}{ Part in which polymer is used } \\
\hline & & Compound & $\%$ weight & Compound & $\%$ weight & \\
\hline PA6,6 & 0.11 & $\mathrm{BPS}+\mathrm{ATO}$ & $18+7$ & Alpi + MPP & $16.7+8.3$ & Connectors, switches \\
\hline EVA & 0.16 & decaBDE + ATO & $13+4$ & ZHS-coated ATH & 70 & Cables \\
\hline PPE/HIPS & 0.52 & decaBDE + ATO & $14+6$ & $\mathrm{RDP}$ & 15 & Casing \\
\hline $\mathrm{PC} / \mathrm{ABS}$ & 0.65 & decaBDE + ATO, & $10+5$ & BDP & 20 & Casing \\
\hline Epoxy resin & 0.29 & TBBPA & 20 & DOPO & 25 & PWB \\
\hline Total laptop weight & 3.15 & & & & & \\
\hline
\end{tabular}

the laptop amounts to $215 \mathrm{kWh}$. Further data can be found in the Electronic Supplementary Material.

\section{Emission factors of flame retardants from plastics During} the use phase of electronic products, FRs can volatilize out of the polymers and thus be released to the environment. According to OECD emission scenarios on plastics additives, the estimated emission factor due to volatilization is $0.05 \%$ over the lifetime of the product (OECD 2004). This emission factor was used for organic additive FRs, and results in total FR emissions in the mg range for the laptop.

Additionally, the OECD scenario estimates an emission factor to water of $0.05 \%$ (for indoor service), which was also included in the current study. For inorganic FRs (for indoor service), emission factors were estimated to be lower: $0.01 \%$ to water and 0 to air (OECD 2004; European Commission 2008a). For decaBDE, more specific emission factor data are used from the EU risk assessment (European Commission 2002). For reactive FRs (DOPO and TBBPA), emission factors were assumed to be 0 in the use phase, as their covalent link to the polymer makes emission unlikely.

Occurrence of fire When considering the life cycle of a laptop, only a minor fraction of the laptops will actually catch fire. When an accidental fire occurs, the different flame retardants in the products may result in different emissions. It was therefore decided to include the occurrence of fire in the study, although in standard LCA practice incidents or unintended processes are usually ignored.

We assumed the presence of one laptop per household and took the average European fire occurrence per household as a value in the current study for the fraction of laptops that will be burnt. This fraction is 0.0094 (9.4 per 1000 households) (Nibra 2009). The fire statistics used can be found in the Electronic Supplementary Material. We assumed the occurrence of fire is independent of the FR (and therefore equal in both the BFR and HFFR scenarios), as all FRs studied comply with V0 fire safety tests.
Emissions from fire Literature data on the emissions (e.g. PAHs, VOCs, dioxins) during the combustion of electronic products was used in both the BFR and HFFR scenarios (Simonson et al. 2000; Andersson et al. 2003, 2004, 2005).

A fraction of the FRs in the polymers may be emitted during combustion. The organic FRs will burn almost completely, while a larger fraction of the inorganic FRs may be emitted intact. For all organic FRs, a small emission factor to air during a fire of $3 \mathrm{E}-7$ was used, based on data from (Simonson et al. 2000). Emission factors of FRs partly depend on the FR's mode of action. ATO acts primarily in the vapour phase (Cusack 2008). In contrast, the inorganic FRs ZHS and ZS are mainly active in the condensed phase, where they contribute to char formation (Cusack 2008). Therefore, emission factors to air will be lower for ZHS and ZS than for ATO. An emission factor of antimony to air of 0.835 for ATO was reported by Simonson et al. (2000). The emission factors to air of ZHS and ZS are assumed to be 10 times lower than for ATO.

As the different FRs have different flame retarding mechanisms, the emissions of other combustion products may also differ between the scenarios.

Tests within the ENFIRO project on the burning behaviour of different FR-polymer combinations yielded data on the emission of $\mathrm{CO}, \mathrm{CO}_{2}$ and smoke. Ratios of emissions for the polymers with HFFR and BFR are shown in Table 4. These data were combined with literature data on emissions from BFR-containing electronics to determine $\mathrm{CO}_{2}, \mathrm{CO}$ and

Table 4 Results from ENFIRO fire experiments for 3 polymers, comparison of $\mathrm{CO}, \mathrm{CO}_{2}$ and smoke emissions for polymer with BFR and polymer with HFFR

\begin{tabular}{llll}
\hline Polymer & \multicolumn{3}{l}{ Ratio of emission with HFFR/ with BFR } \\
\cline { 2 - 4 } & $\mathrm{CO}$ & $\mathrm{CO}_{2}$ & Smoke \\
\hline PC/ABS & 0.76 & 1.15 & 0.84 \\
PPE/HIPS & 0.73 & 2.18 & 0.90 \\
PA6,6 & 0.37 & 0.89 & 0.37 \\
\hline
\end{tabular}


Table 5 Emissions from burning electronics, for the scenario with BFRs and with HFFRs. Adjustments are based on the ratios in Table 4, and the amounts of each polymer in the laptop

\begin{tabular}{llll}
\hline $\begin{array}{l}\text { Chemical emission } \\
\text { (g per kg combustible material) }\end{array}$ & $\mathrm{CO}$ & $\mathrm{CO}_{2}$ & $\begin{array}{l}\text { Particulate } \\
\text { matter, }<10 \mu \mathrm{m}\end{array}$ \\
\hline BFR scenario & 86 & 2400 & 50 \\
HFFR scenario & 68 & 3300 & 44 \\
\hline
\end{tabular}

particulate matter emissions for both scenarios, as shown in Table 5 (Simonson et al. 2000; Blomqvist 2005).

\subsubsection{End of Life scenarios}

The end-of-life scenarios considered for the laptop were:

- Collection and treatment according to the WEEE Directive

- Disposal with municipal waste, followed by incineration in municipal solid waste incinerator (MSWI)

- Disposal with municipal waste, followed by dump on landfill

- Export, followed by substandard waste treatment
The percentages of WEEE ending up in the different treatment systems are a subject of heated international debate. Estimations by different stakeholders differ strongly (Cobbing 2008; European Commission 2008b; Perkins et al. 2014; Robinson 2009; WEEE forum 2010). A detailed investigation on WEEE flows is available for The Netherlands (Huisman et al. 2012). This study included both the official WEEE collection systems and the "unofficial' complementary WEEE collection streams, as well as export streams of WEEE plus (still functioning) used equipment (EEE). The WEEE amounts quantified for the category 'IT equipment' were slightly adjusted for the European situation (e.g. $38 \%$ landfill of municipal waste in Europe and $0 \%$ in The Netherlands) (European Commission 2010). In addition, it was assumed that half of the exported WEEE flow will end up in improper waste treatment under substandard conditions (and the other half ending up in municipal waste). This results in a total fraction of WEEE treated improperly of 0.19 . Fractions of WEEE ending up in the different scenarios are shown in Table 6.

Treatment according to WEEE Directive Foreground data on WEEE treatment according to the WEEE-Directive were obtained from Stena Metall, a Swedish recycling company (Sjölin 2012). After a pretreatment, the WEEE is either

Table 6 Amounts of WEEE ending up in different waste treatment methods for the subcategory IT (based on Huisman et al. 2012)

\begin{tabular}{|c|c|c|c|c|c|}
\hline & $\mathrm{kg} /$ inhabitant/year & Fraction of WEEE+ used EEE & Further specification, bas & d on own assumptions & Fraction \\
\hline EEE put on market (POM) & 3.03 & & & & \\
\hline WEEE + used EEE generated & 3.00 & & & & \\
\hline \multirow[t]{3}{*}{ Export of used EEE } & 0.60 & 0.20 & Municipal waste & Incineration & $0.033^{\mathrm{a}}$ \\
\hline & & & & Landfill & $0.066^{\mathrm{a}}$ \\
\hline & & & Substandard treatment & & $0.10^{\mathrm{a}}$ \\
\hline WEEE generated & 2.40 & 0.80 & & & \\
\hline \multicolumn{6}{|l|}{$\begin{array}{l}\text { Collection and treatment according } \\
\text { to WEEE Directive: }\end{array}$} \\
\hline Via official WEEE route & 0.61 & & & & \\
\hline Via complementary routes & 0.70 & & & & \\
\hline Total proper WEEE treatment & 1.31 & 0.44 & & & \\
\hline \multirow[t]{2}{*}{ WEEE ending up in municipal waste } & 0.54 & 0.18 & Incineration & & $0.06^{\mathrm{a}}$ \\
\hline & & & Landfill & & $0.12^{\mathrm{a}}$ \\
\hline \multirow[t]{3}{*}{ Not (yet) documented } & 0.55 & 0.18 & Municipal waste & Incineration & $0.03^{\mathrm{a}}$ \\
\hline & & & & Landfill & $0.06^{\mathrm{a}}$ \\
\hline & & & Substandard treatment & & $0.09^{\mathrm{a}}$ \\
\hline \multirow[t]{4}{*}{ Total fractions of waste streams } & \multicolumn{2}{|c|}{ Treated according to WEEE Directive } & & & $0.44^{\mathrm{a}}$ \\
\hline & \multicolumn{2}{|c|}{ Incineration } & & & $0.12^{\mathrm{a}}$ \\
\hline & \multicolumn{2}{|l|}{ Landfill } & & & $0.25^{\mathrm{a}}$ \\
\hline & \multicolumn{2}{|c|}{ Substandard treatment } & & & $0.19^{\mathrm{a}}$ \\
\hline
\end{tabular}

${ }^{\mathrm{a}}$ These values are not mentioned in Huisman et al. 2012, but based on own assumptions, see main text 
manually dismantled and then shredded or processed in an automatic shredder without dismantling. Fragmented scrap is then sorted by flotation methods. The non-brominated plastic fraction will go to material recycling, and the brominated plastic fraction is incinerated as hazardous waste.

Municipal solid waste incineration The model of this scenario was based on the Ecoinvent process sheets 'Disposal, residues, mechanical treatment, laptop computer, in MSWI' and 'Disposal, plastic, consumer electronics, to municipal incineration'. The emission factors from MSWI incineration for inorganic FRs were all assumed to be equal to the values reported in the EU risk assessment on ATO (European Commission 2008a). For organic FRs, the emission factor to air was assumed to be 10 times lower than the estimated emission factor during accidental fire.

Landfill This waste scenario was based on the Ecoinvent process sheets 'Disposal, plastics, mixture, to sanitary landfill' and 'Disposal, inert material, to sanitary landfill'. Leaching of FRs from landfill was incorporated based on laboratory experiments performed within the ENFIRO project. These experiments resulted in 20-day leaching values, which were extrapolated to an assumed residence time on the landfill of 25 years. Further details can be found in the Electronic Supplementary Material.

Export and substandard treatment In this scenario, after shipping the WEEE to Asia and Africa, rudimentary recycling techniques are applied to recover part of the metals. These practices often take place with little regard for worker safety or environmental consequences (Kuper and Hojsik 2008; Nnorom and Osibanjo 2008; Nordbrand 2009; Sepúlveda et al. 2010). Emissions are expected during open burning of cables and circuit boards to retrieve metals, desoldering or acid leaching of printed wiring boards, and manual dismantling of flat panel displays with mercury-containing lamps (Sepúlveda et al. 2010; Wang 2012). Emissions include lead, tin, cadmium, mercury, acid fumes, cyanide and chlorinated and brominated dioxins.

For emissions from combustion of the organic components of the laptop, the same inventory data was used as for the combustion during accidental fire (see paragraph Emissions from fire). Emission factors of particulate matter and metals were derived from simulated WEEE recycling experiments reported by Gullett et al. (2007).

The formation of dioxins is one of the most discussed hazard issues concerning substandard WEEE treatment. Brominated dioxins can be formed out of BFRs, but (chlorinated) dioxins can also be formed out of other WEEE components, such as PVC.

Literature on laboratory studies of formation of dioxins out of WEEE and BFRs was used in combination with the composition of the laptop to derive dioxin emission factors for improper WEEE treatment (Gullett et al. 2007; Weber and
Kuch 2003). This resulted in an emission of $0.51 \mathrm{mg}$ TEQ per kg WEEE. Strongly differing results from literature indicate a large uncertainty of this value. More details can be found in the Electronic Supplementary Material.

\subsection{Impact assessment}

The impact assessment method ReCiPe 1.03 (Endpoint) was applied in this study. The full range of environmental impact categories from this method was considered. Toxicity characterization factors for FRs which are not included in the ReCiPe method were calculated in a procedure identical to the one used for the other toxicity characterization factors in ReCiPe by application of the multimedia fate, exposure and effects model USES-LCA2 (Van Zelm et al. 2009). Physicochemical properties of FRs needed in the model were partly found in literature (Waaijers et al. 2013) and partly derived from results of fugacity-based multimedia modeling within the ENFIRO project. The toxicity characterization factors thus determined are listed in Table 7.

\section{Results}

As the focus of this study is on toxic flame retardants and their substitutes, the toxicity impact categories of the ReCiPe method are considered as most relevant when discussing the results. In addition, climate change scores are discussed, and single score results are considered as well.

Values corresponding to the figures can be found in the Electronic Supplementary Material.

\subsection{Production of flame retardants and flame retarded polymers}

Figures 2 and 3 show a comparison of the production of $1 \mathrm{~kg}$ of each of the FRs investigated ('cradle-to-gate'). The separate toxicity categories in Fig. 2 show that ATO scores are highest for human toxicity. This is caused by heavy metal emissions during the mining phase. During mining of zinc and tin ore, heavy metal emissions also lead to a relatively high human toxicity score for ZHS and ZS.

Relatively high human toxicity, terrestrial and freshwater ecotoxicity scores are also observed for RDP, BDP and DOPO: This is caused by the emission of white phosphorus to air during production of intermediary products in the production route $\left(\mathrm{POCl}_{3}\right.$ and $\left.\mathrm{PCl}_{3}\right)$. According to the database background information, these values are based on estimations, and therefore, the uncertainty in this result is relatively high. For marine ecotoxicity, ZHS and ZS have the highest scores, which is caused by emissions of ZS and ZHS.

In Fig. 3, total LCA scores for the production of $1 \mathrm{~kg}$ FR are shown. Large differences are found between FRs, with a 
Table 7 Toxicity characterization factors for flame retardants, calculated with USES-LCA2, in line with the ReCiPe Endpoint method. ND: not determined for lack of reliable toxicity data

\begin{tabular}{|c|c|c|c|c|c|c|c|c|}
\hline \multirow[t]{3}{*}{ Flame retardant } & \multirow{2}{*}{\multicolumn{2}{|c|}{$\begin{array}{l}\begin{array}{l}\text { Human toxicity } \\
\text { (DALY/kg) }\end{array} \\
\text { Emission to: }\end{array}$}} & \multirow{2}{*}{\multicolumn{2}{|c|}{$\begin{array}{l}\text { Freshwater ecotoxicity } \\
(\text { species } \times \text { year } / \mathrm{kg})\end{array}$}} & \multirow{2}{*}{\multicolumn{2}{|c|}{$\begin{array}{l}\text { Marine water ecotoxicity } \\
(\text { species } \times \text { year } / \mathrm{kg})\end{array}$}} & \multirow{2}{*}{\multicolumn{2}{|c|}{$\begin{array}{l}\begin{array}{l}\text { Terrestrial ecotoxicity } \\
(\text { species } \times \text { year } / \mathrm{kg})\end{array} \\
\text { Emission to: }\end{array}$}} \\
\hline & & & & & & & & \\
\hline & Freshwater & Air & Freshwater & Air & Freshwater & Air & Freshwater & Air \\
\hline $\mathrm{AlPi}$ & $1.6 \mathrm{E}-09$ & $5.9 \mathrm{E}-08$ & $6.9 \mathrm{E}-09$ & $2.8 \mathrm{E}-09$ & $6.0 \mathrm{E}-09$ & 4.5E-09 & $9.8 \mathrm{E}-13$ & $9.7 \mathrm{E}-07$ \\
\hline APP & 7.2E-09 & $2.7 \mathrm{E}-07$ & 7.9E-10 & 3.3E-10 & $6.9 \mathrm{E}-10$ & $5.0 \mathrm{E}-10$ & $9.0 \mathrm{E}-13$ & $1.2 \mathrm{E}-07$ \\
\hline ATH & 7.6E-10 & $3.0 \mathrm{E}-08$ & 7.3E-10 & $8.1 \mathrm{E}-11$ & $5.3 \mathrm{E}-10$ & $6.3 \mathrm{E}-10$ & $3.3 \mathrm{E}-29$ & 7.7E-08 \\
\hline ATO & $7.8 \mathrm{E}-11$ & $8.5 \mathrm{E}-10$ & $6.0 \mathrm{E}-08$ & 6.7E-09 & $5.2 \mathrm{E}-08$ & $2.3 \mathrm{E}-08$ & $1.9 \mathrm{E}-27$ & $1.7 \mathrm{E}-06$ \\
\hline BDP & ND & ND & 1.9E-09 & $6.8 \mathrm{E}-13$ & $1.4 \mathrm{E}-09$ & $9.4 \mathrm{E}-11$ & 7.6E-18 & 7.1E-11 \\
\hline decaBDE & $2.0 \mathrm{E}-03$ & $7.1 \mathrm{E}-04$ & ND & ND & ND & ND & ND & ND \\
\hline DOPO & $1.2 \mathrm{E}-09$ & 4.4E-09 & 1.4E-08 & 3.3E-09 & $1.2 \mathrm{E}-08$ & 8.0E-09 & $3.7 \mathrm{E}-13$ & $8.2 \mathrm{E}-07$ \\
\hline RDP & ND & ND & $2.2 \mathrm{E}-09$ & $2.0 \mathrm{E}-11$ & $1.4 \mathrm{E}-09$ & 3.9E-09 & $1.0 \mathrm{E}-17$ & $1.1 \mathrm{E}-09$ \\
\hline TBBPA & 3.9E-08 & $5.1 \mathrm{E}-07$ & $2.6 \mathrm{E}-08$ & $2.1 \mathrm{E}-10$ & $2.1 \mathrm{E}-10$ & $1.5 \mathrm{E}-09$ & $2.0 \mathrm{E}-12$ & 3.4E-09 \\
\hline ZHS & ND & ND & $2.1 \mathrm{E}-08$ & 2.3E-09 & $1.8 \mathrm{E}-08$ & 7.9E-09 & $6.5 \mathrm{E}-28$ & $5.9 \mathrm{E}-07$ \\
\hline ZS & ND & ND & $2.1 \mathrm{E}-08$ & 2.3E-09 & $1.8 \mathrm{E}-08$ & 7.9E-09 & $7.0 \mathrm{E}-28$ & 5.9E-07 \\
\hline
\end{tabular}

factor of 32 between the highest and lowest scores (ZS and $\mathrm{ATH}$, respectively).

For most FRs, the largest contributions to the score are energy use related, with relatively high scores for climate change and fossil depletion. The inorganic FRs ATO, ZS and ZHS have in addition high scores for particulate matter formation and metal depletion, which are both related to the mining phase.

Of more practical significance than a direct comparison of FRs (which vary in loading rates and compatibility with different polymer types) is the comparison of compounded FR- polymer combinations, which fulfil the V0 fire safety requirements.

A comparison of flame-retarded polymers is shown in Fig. 4 (cradle-to-gate). For each of the polymers, a BFRcontaining version, an HFFR-containing version and a non-flame retarded version are shown (polymer without additive). Variations between the BFR and HFFR polymer versions are relatively small (compared to differences found for production of FRs): A maximum difference of $16 \%$ is observed within polymer types. This is partly because the production of polymer has a high contribution to
Fig. 2 LCA scores for the production of $1 \mathrm{~kg}$ flame retardant, cradle-to-gate, for the four toxicity impact categories and climate change of the ReCiPe method. Each category is expressed as fraction of the FR with the maximum score

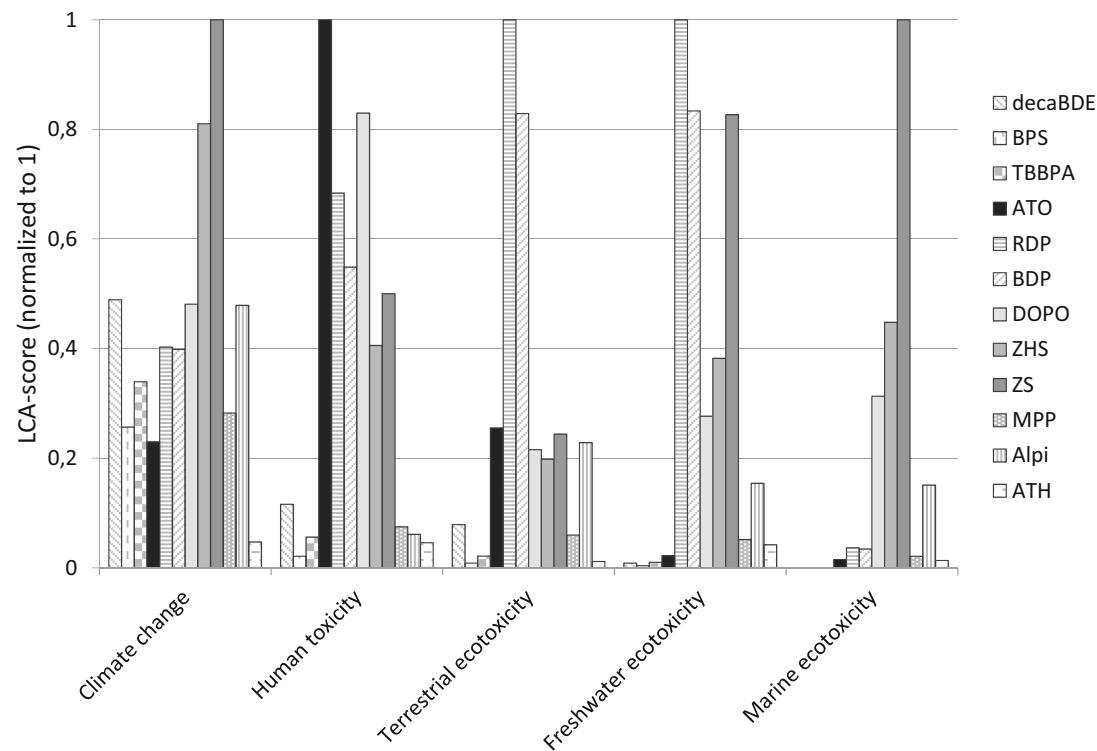


Fig. 3 Environmental impact for the production of $1 \mathrm{~kg}$ flame retardant, cradle-to-gate ( $\mathrm{ReCiPe}$ Single Score results)

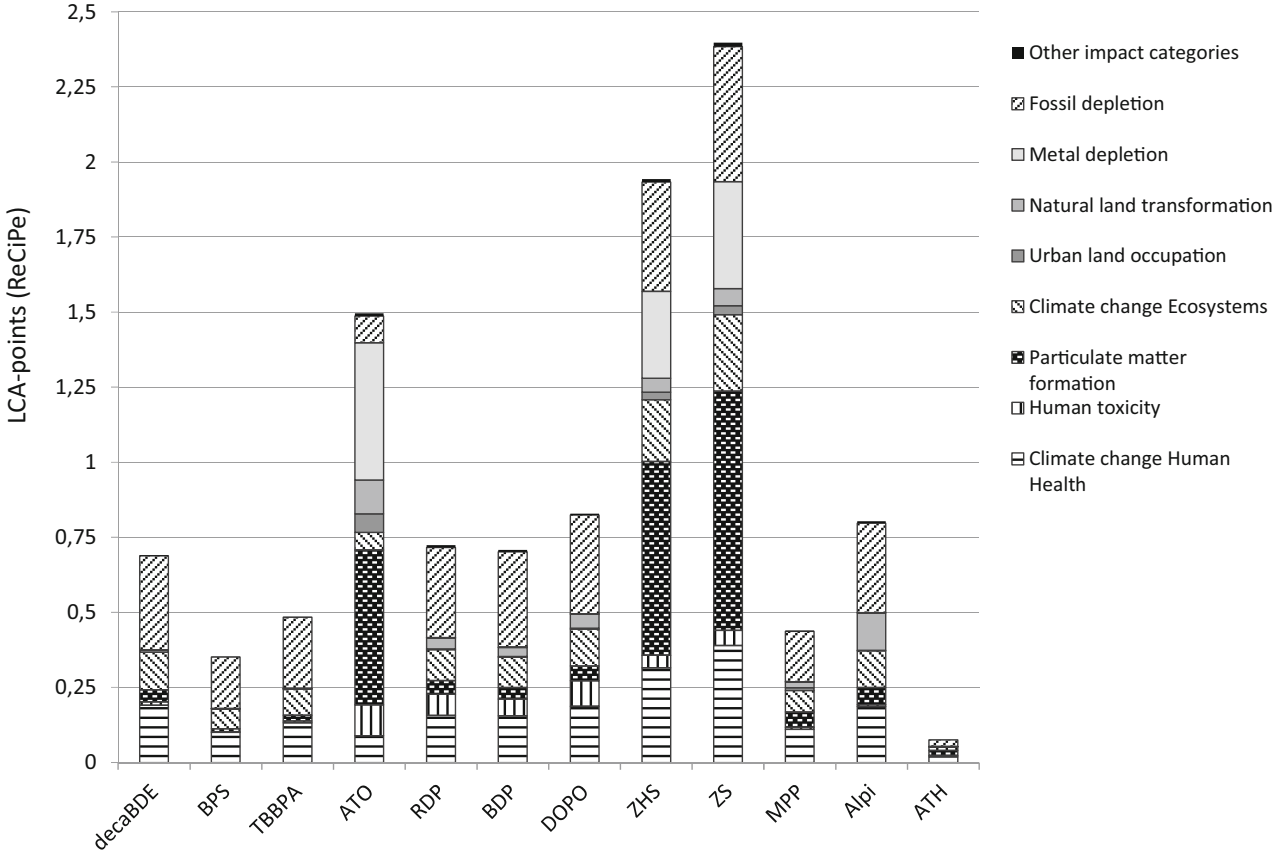

the score and partly because the FRs with high impact per $\mathrm{kg}$ are used at lower loading rates, while FRs with low impact per $\mathrm{kg}$ are used at higher loading rates.

\subsection{Use phase}

\subsubsection{Emissions during use}

Due to volatilization of FRs from the polymers, emissions can occur during the use phase. A comparison of this process for the BFR and HFFR scenarios is shown in Fig. 5. Human toxicity and freshwater ecotoxicity score highest in the BFR scenario, while the terrestrial and marine ecotoxicity scores are highest for the HFFR scenario.

The single score result is highest for the BFR scenario, which is mainly due to the human toxicity score of the emission of decaBDE $(4.2 \mathrm{mPt})$. The terrestrial ecotoxicity score in the HFFR scenario $(0.023 \mathrm{mPt})$ is mainly due to emissions of Alpi and MPP, while the scores for freshwater and marine ecotoxicity are caused mainly by RDP, BDP, Alpi and ZHS (HFFR scenario) and ATO (BFR scenario).
Fig. 4 Environmental impact for the production of $1 \mathrm{~kg}$ flame retarded polymer, cradle-to-gate (ReCiPe Single Score results). Different loading rates required for different FRs (see Table 3) are included in these calculations

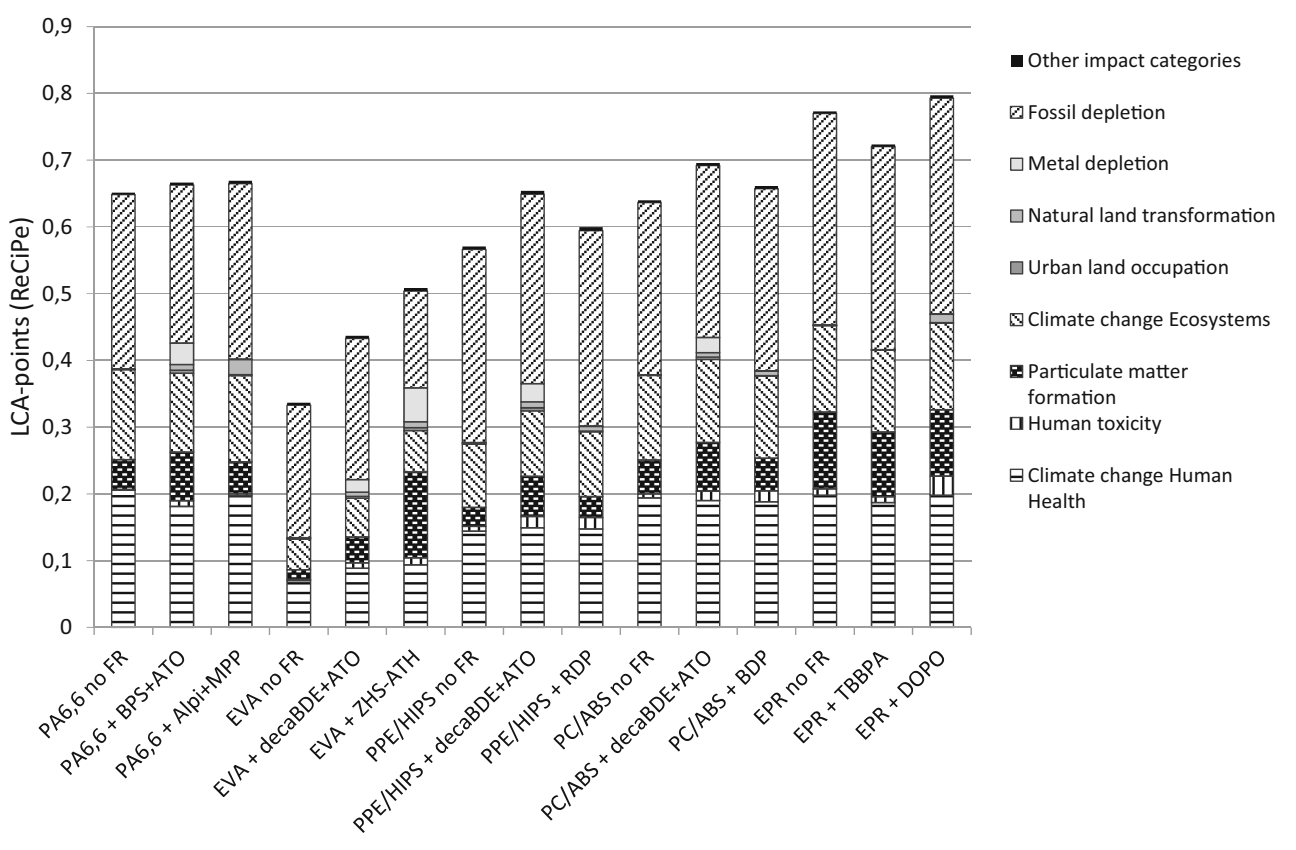




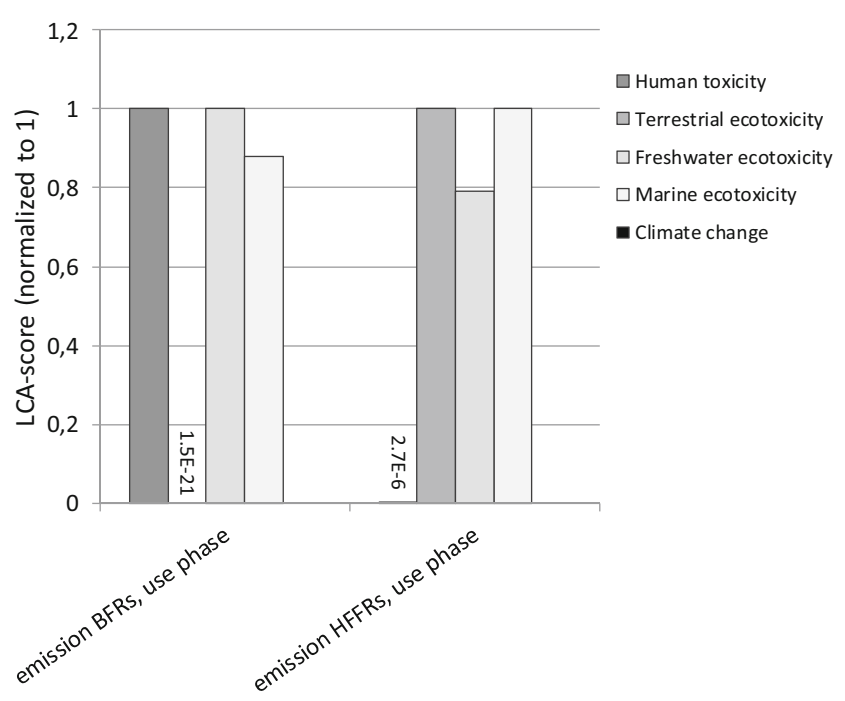

Fig. 5 Environmental impact for FR emissions during the use phase of a laptop with BFRs and a laptop with HFFRs, for the four toxicity impact categories and climate change of the ReCiPe method. Each category is expressed as fraction of the FR with the maximum score

When considering the overall use phase including electricity use of the laptop, we find that scores for human toxicity and terrestrial ecotoxicity are at least two orders of magnitude higher for electricity use than for volatilization of FRs. Scores for marine ecotoxicity are comparable for electricity use and FR volatilization. For freshwater toxicity in the BFR scenario, they are comparable as well, while in the HFFR scenario electricity use scores two orders of magnitude higher than FR volatilization.

\subsubsection{Accidental fire}

A small fraction of the laptops will end up in accidental fire. Some of the emissions during combustion of a laptop will vary with the presence of different FRs. Figure 6 shows total LCA scores for the combustion of a complete laptop for the BFR and HFFR scenario. A relatively high score for terrestrial ecotoxicity in the BFR scenario is observed. This is caused mainly by the emission of ATO (active as FR in the vapour phase), which has a higher emission factor to air than other FRs. The higher rate of smoke formation in the BFR scenario leads to a higher score for particulate matter formation. $\mathrm{CO}_{2}$ emissions are higher in the HFFR scenario than in the BFR scenario, resulting in higher scores for climate change. The single score result for accidental fire is $26 \%$ higher for the BFR scenario than for the HFFR scenario. As mentioned in paragraph Occurrence of fire, the occurrence of fire in both life cycle scenarios is assumed to be equally low.

\subsection{End of life}

In Figs. 7 and 8, LCA scores of the waste treatment options for a complete laptop are shown. Each scenario represents one complete laptop. For all toxicity impact categories, the BFR scenario scores higher than the HFFR scenario. For human toxicity and terrestrial ecotoxicity, the improper treatment has the highest score of all waste treatment options for both the BFR and HFFR scenario. Human toxicity for improper treatment in the BFR scenario is mainly caused by the formation of (brominated) dioxins during incomplete incineration of BFRs. In the HFFR scenario, the human toxicity score for improper treatment is mainly caused by emissions of lead, arsenic, hydrogen fluoride, PAHs and other chemicals (which all occur in the BFR scenario as well).

A number of emissions contribute to the scores for terrestrial ecotoxicity, mainly bromine, copper, cyanide, PAHs and the FRs ATO, ZHS and ATH. Scores for freshwater and
Fig. 6 Environmental impact for accidental combustion of a laptop with BFRs and a laptop with HFFRs (ReCiPe single score results). The fraction of laptops actually ending up in an accidental fire is not incorporated in this figure

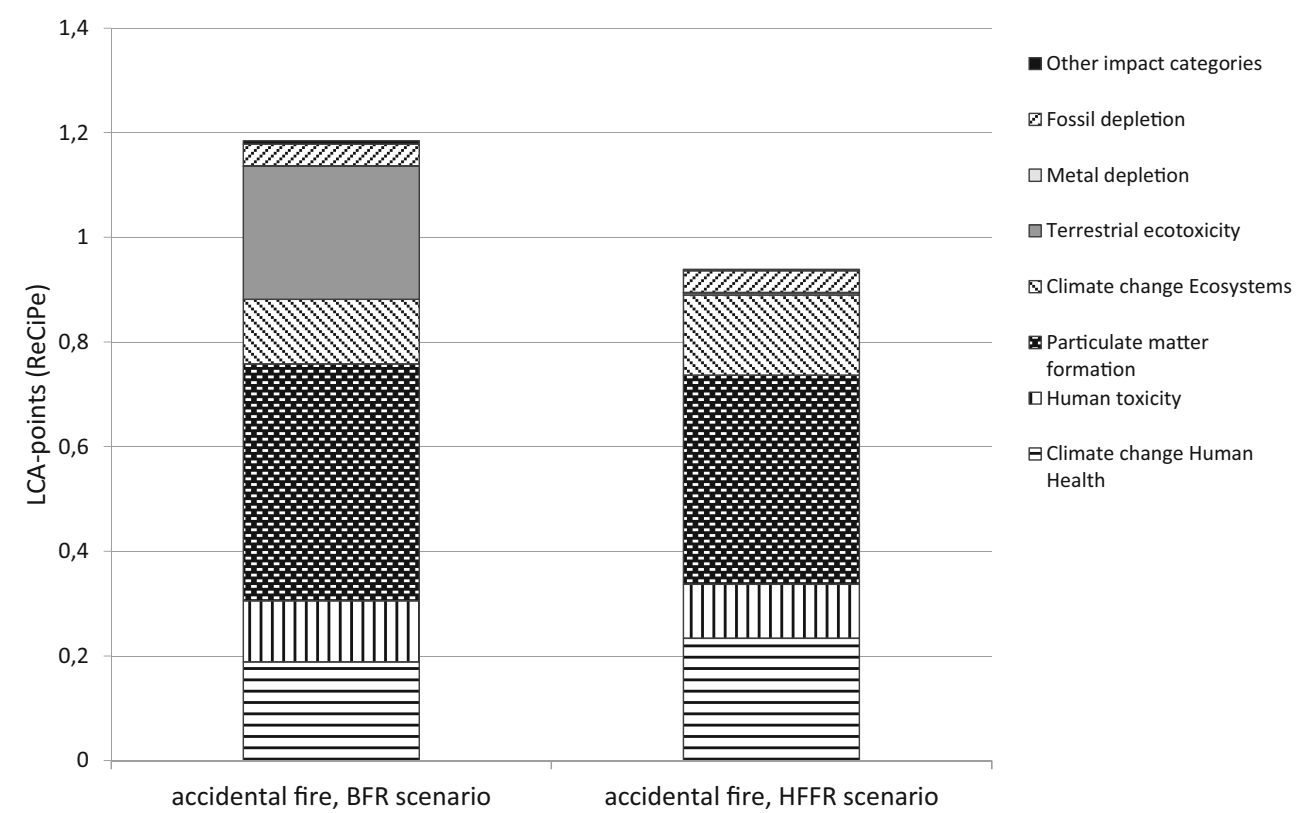


Fig. 7 Environmental impact for the end-of-life treatment of 1 laptop. A laptop with BFRs and a laptop with HFFRs are compared for the 4 end-of-life options. Scores are shown for the four toxicity impact categories and climate change of the ReCiPe method. Each category is expressed as fraction of the FR with the maximum score. Each scenario represents one complete laptop

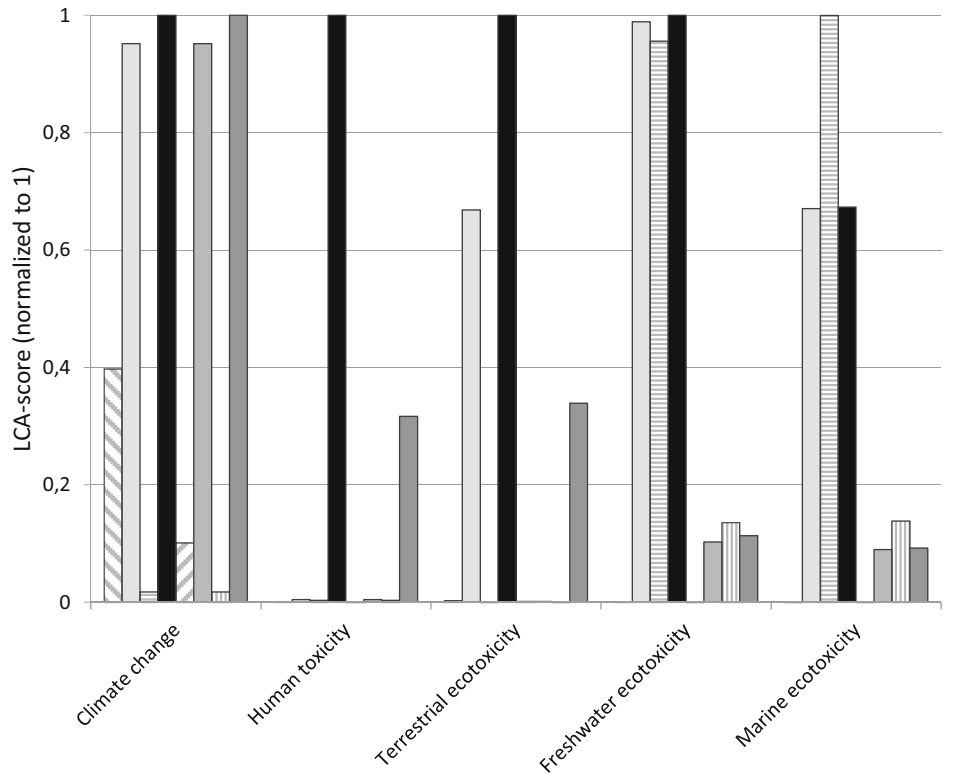

$\square$ WEEE-compliant treatment, BFR

$\square$ Incineration in MSWI, BFR

日Landfill, BFR

- Export \& improper treatment, BFR $\square$ WEEE-compliant treatment, HFFR $\square$ Incineration in MSWI, HFFR $\square$ Landfill, HFFR $\square$ Export \& improper treatment, HFFR marine ecotoxicity are mainly caused by ATO, bromine and several heavy metals (BFR scenario) and the FRs ZHS, ATH and Alpi (HFFR scenario).

The MSWI and improper treatment option have the highest climate change scores, as in both cases the laptop is incinerated. Climate change scores for the WEEE-compliant treatment are higher for the BFR version than for the HFFR version because, in the BFR version, a higher percentage of the polymers (all bromine containing polymers) is incinerated instead of recycled.

For the total scores of the waste treatment options shown in Fig. 8, the improper treatment option has the highest total score in both the BFR and HFFR scenario, mainly due to high contributions of the human toxicity impact category. In both scenarios, the second highest score is for incineration in a normal MSWI, followed by the WEEE-compliant treatment procedure and, finally, landfill.

\subsection{Full life cycle}

ReCiPe single scores for each phase in the life cycle of a BFRand a HFFR-containing laptop are shown in Fig. 9. The highest scores are observed for the production of different laptop components (PWBs, LCD screen and batteries). Another high contribution to the overall environmental impact comes from electricity use of the laptop during the use phase.
Fig. 8 Environmental impact for the end-of-life treatment of 1 laptop (ReCiPe single score results). A laptop with BFRs and a laptop with HFFRs are compared for the 4 end-of-life options. Each scenario represents one complete laptop

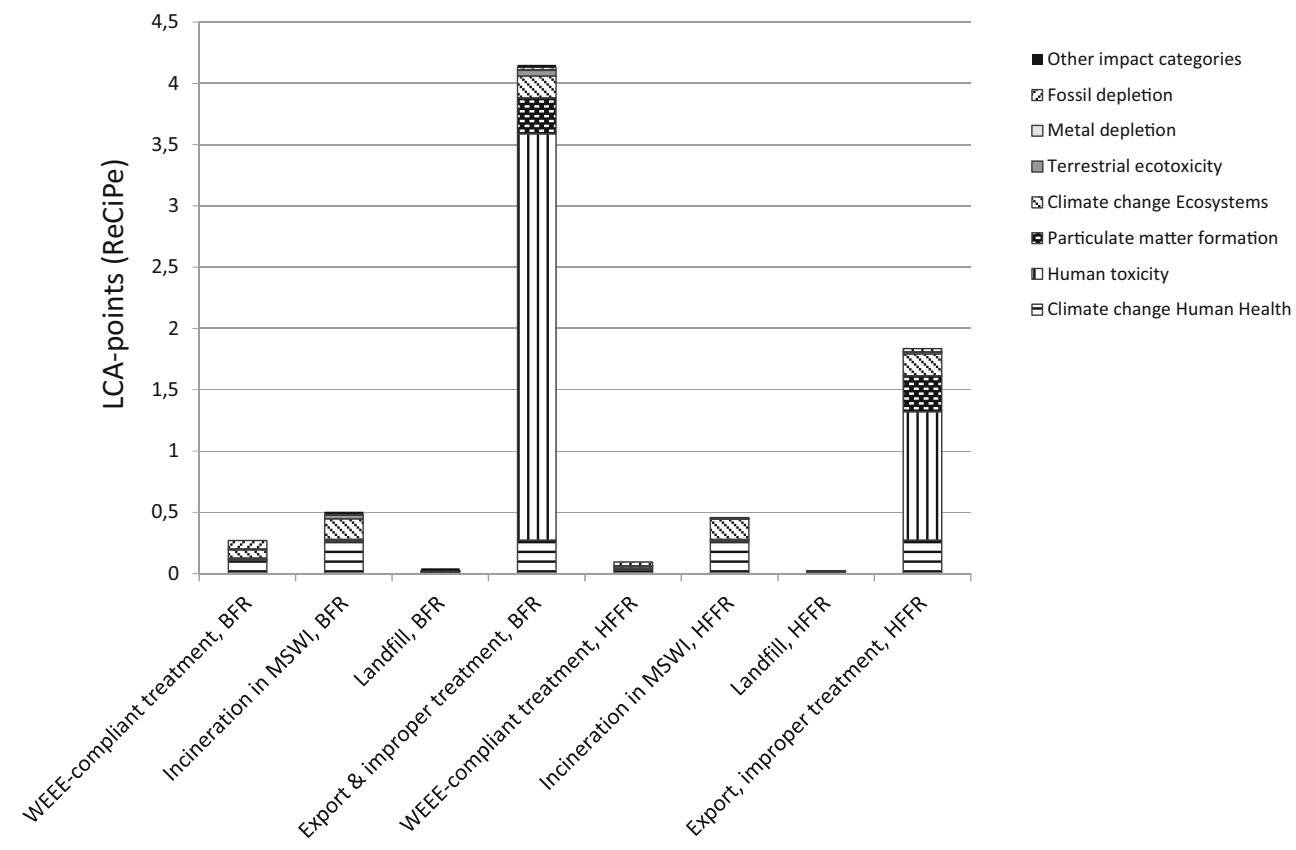


Fig. 9 a Environmental impact (ReCiPe single score results) for each phase of the life cycle of the laptop scenario containing BFRs (left column of each pair) or HFFRs (right column of each pair). b The same results with an adjusted Y-scale to show the processes/phases with lower scores
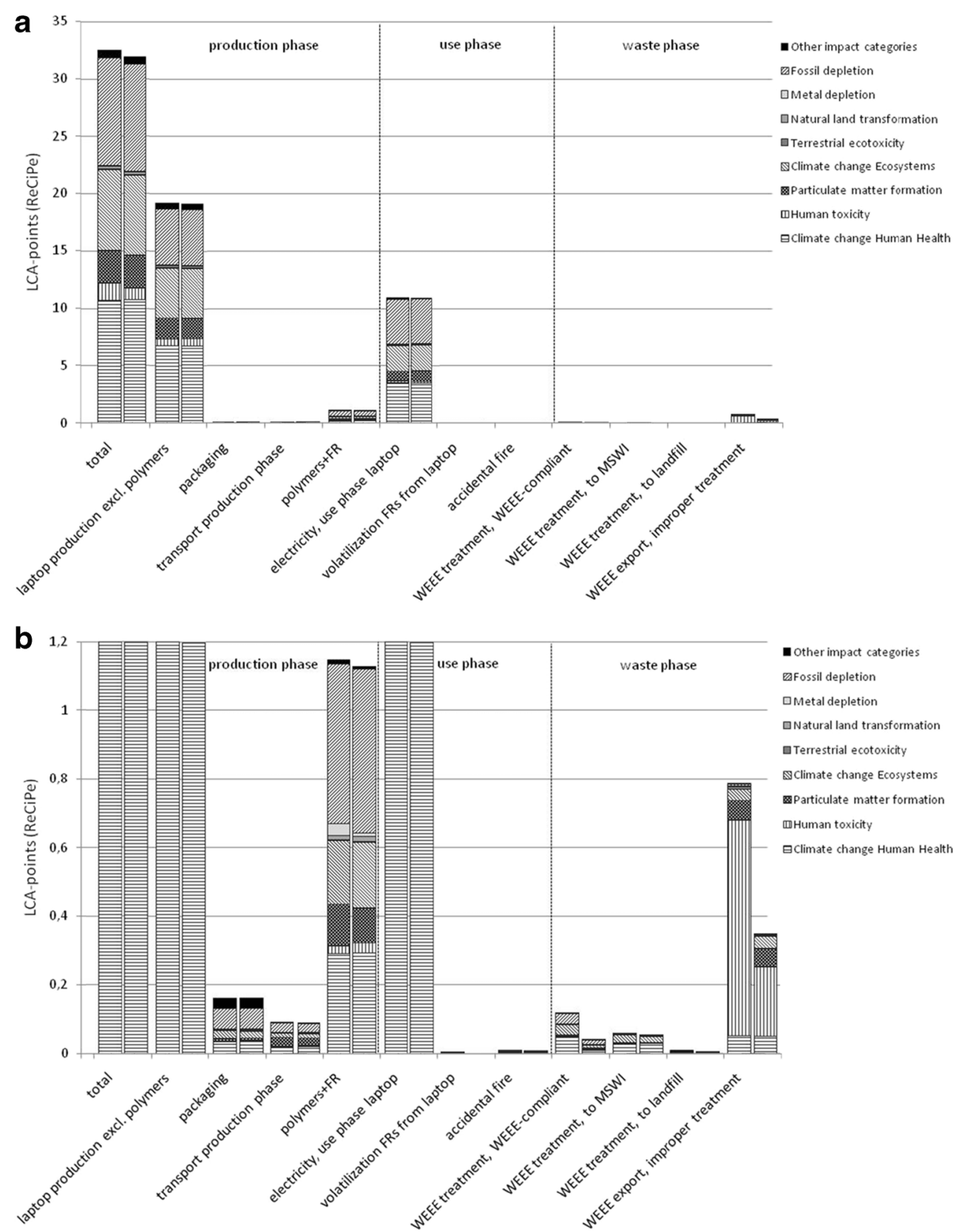

The scores in these processes are all independent of the choice of FRs (all polymer materials in those components were modelled as separate processes).

Of the processes that are influenced by the FRs, the highest score is for the production phase of the five flame-retarded polymers. The second highest impact occurs during improper waste treatment. The contribution to the overall environmental impact by volatilization of FRs in the use phase and emissions from accidental fire is low.

Of the four end-of-life options, the highest impact occurs for export followed by improper treatment. For BFRs, the end-of-life option with the second highest impact is WEEEDirective compliant treatment. This is mainly due to the high percentage of WEEE ending up in this waste scenario. In contrast, for the HFFR scenario, the end-of-life option with the second highest impact is incineration in an MSWI. Landfill is the end-of-life option with the lowest impact for both the BFR and HFFR scenario.

For all phases of the life cycle except improper waste treatment, the impact scores are dominated by the impact categories climate change, fossil depletion and particulate matter formation, which are mainly related to fossil energy consumption. In the improper waste treatment phase, human toxicity has the largest contribution to the score.

The overall environmental impact of the life cycle of the BFR containing laptop is only marginally higher than the 
HFFR containing laptop (32.5 and $32.0 \mathrm{Pt}$, respectively). The largest differences are found for human toxicity in the improper treatment phase. A relatively large difference in the WEEEDirective compliant waste treatment phase is found as well (because in the BFR scenario, a higher fraction of polymers is incinerated instead of recycled).

In the production phase of the flame-retarded polymers, smaller differences are found, with the total impact of the production of the five flame-retarded polymers being slightly higher for the BFR scenario.

Relatively, small differences are found between the BFR and HFFR scenario for FR volatilization during the use phase, emissions during accidental fire, during incineration in a MSWI and for the WEEE fraction ending up on a landfill. The BFR scenario impacts are slightly higher in these life cycle phases.

Figure 10 shows the scores of BFR and HFFR full life cycle scenarios for each impact category, expressed as fraction of the highest score (100\%). For many impact categories, the scores of both scenarios are almost equal, and FR-related contributions to the score are minor. The main differences between the scenarios are observed for the impact categories human toxicity, terrestrial, marine and freshwater ecotoxicity and metal depletion. For these five impact categories, the impact is lower in the HFFR scenario.

\section{Discussion}

\subsection{Impact categories most relevant to flame retardants}

In most phases of the life cycle of FRs, fossil energy userelated impact categories dominate the LCA score: climate change, fossil depletion and particulate matter formation. The life cycle phases in which human toxicity and ecotoxicity of FRs play a relevant role are: export of WEEE followed by substandard waste treatment and to a lesser extent the other waste treatment options. Only a minor fraction of the FRs present in the product is emitted during volatilization in the use phase, and only a minor fraction of the laptops is exposed to accidental fire. Therefore, these two processes do not contribute much to the scores for toxicity.

The main differences between the two full life cycle scenarios are found for the impact categories human toxicity, ecotoxicity and metal depletion, as shown in Fig. 10. For these impact categories, the impact is lower in the HFFR scenario. For the other impact categories, the scores of both full life cycle scenarios are almost equal.

\subsection{Processes most relevant to flame retardants}

The environmental impact in the production phase of FRs (cradle-to-gate, per kg) varies considerably. The highest total impacts are found for ZS, ZHS and ATO. Lower total impacts are found for decaBDE, RDP, BDP, DOPO and Alpi, followed by TBBPA, MPP and BPS. The lowest impact is found for the production of ATH. For the production of flame-retarded polymers, differences in environmental impact between BFR and HFFR containing polymers are smaller.

The emissions of FRs through volatilization in the use phase have only a small contribution to the overall impact over the complete life cycle, but this phase is still likely to be the most important exposure route for humans.

In the case of accidental fire, the BFR scenario has a higher overall impact than the HFFR scenario due to a higher rate of
Fig. 10 Comparison of scenarios: normalized characterization results for the complete life cycle of the scenario with BFRs (dark bars) and with HFFRs (light bars). Striped segments indicate the contribution of FR-related processes to the score. Solid segments indicate the contribution of all other processes

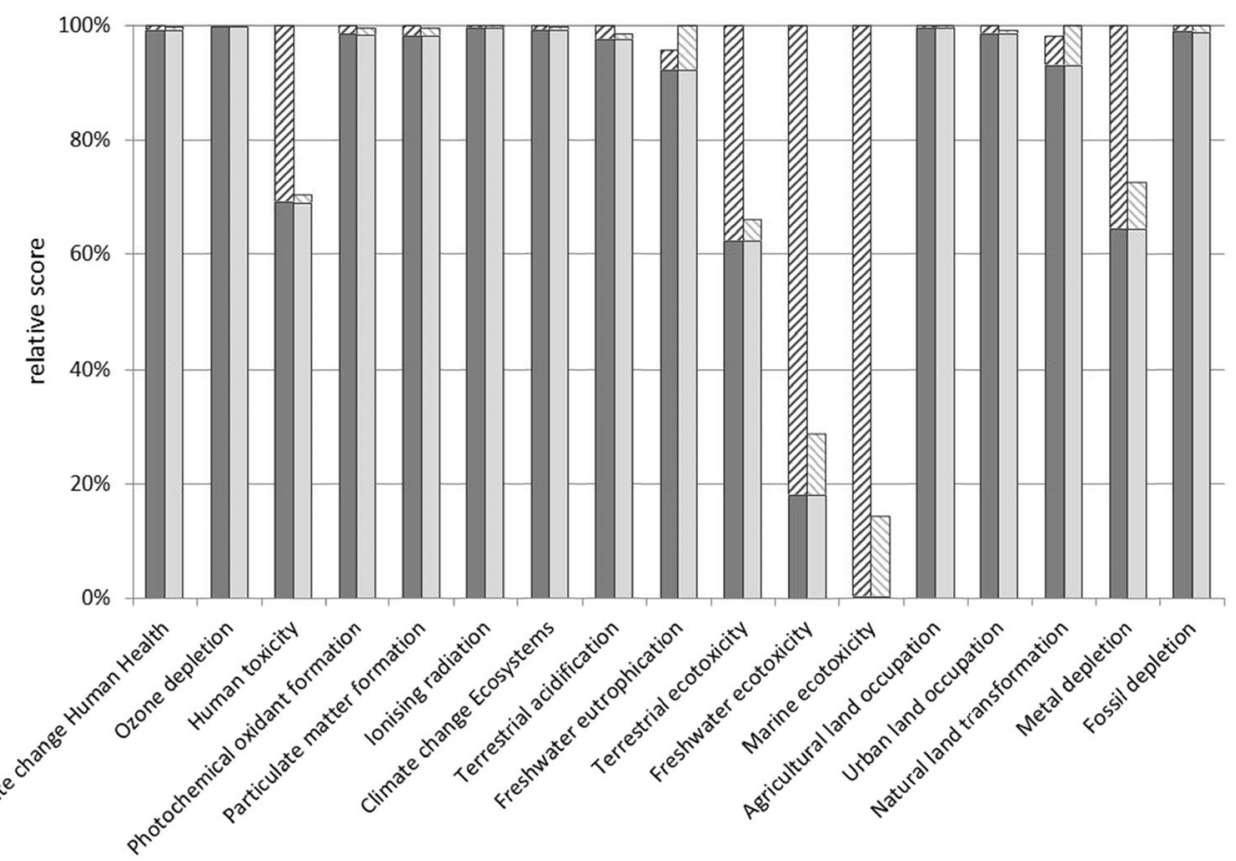


smoke formation and a higher terrestrial ecotoxicity score. In the HFFR scenario, the score for climate change is higher than in the BFR scenario due to higher $\mathrm{CO}_{2}$ emissions (more complete combustion).

Of the four end-of-life scenarios for WEEE, the option 'export followed by improper treatment' has the highest environmental impact for both the BFR and HFFR scenarios. In the BFR scenario, this high impact is mainly caused by the formation of (brominated) dioxins during improper WEEE incineration. The high LCA score for improper WEEE treatment in the HFFR as well as the BFR scenario shows that even when BFRs are substituted by HFFRs, these practices will remain quite hazardous, as there is a range of toxic emissions during improper treatment. Efforts should continue (or be intensified) to reduce the amount of European WEEE ending up in this scenario.

\subsection{Data quality}

In this LCA study, a diverse set of processes concerning the life cycle of FRs is addressed. A consequence of this diversity is that the data used in the study has a wide range of sources and quality. The 'chaotic' nature of accidental fire and improper WEEE treatment makes it hard to obtain reliable data on chemical emissions for these processes. Literature or experimental data was used in these cases, reflecting the current state of knowledge on these issues. Sensitivity analyses for several key parameters can be found in the Electronic Supplementary Material.

\subsection{Processes normally not included in LCA}

The following issues are not often included in LCA studies:

- Polymer additives (flame retardants), including emissions in all life cycle phases

- Substandard waste treatment

- Occurrence of accidental fire

These issues have been incorporated in the current study. The LCA results show the potential impact of these processes within the complete life cycle of the electronics product and the specific influence of different FRs on these impacts. Further evaluations of these topics are necessary. More focused risk assessment studies would yield more detailed knowledge of the potential risks involved in these processes. The valuable complementary roles of LCA and risk assessment have been discussed in several papers (Askham 2012; Askham et al. 2013; Matthews et al. 2002; Socolof and Geibig 2006).

The relatively high impact of improper WEEE treatment as modelled in this study shows the potential relevance of 'unofficial' end-of-life options. Future LCA studies should increasingly include these issues to allow LCA results to keep contributing to discussions in society and policy on the current sustainability issues of electronics.

\section{Conclusions and recommendations}

In this LCA study, a comparison is made between the overall environmental impact of two sets of flame retardants in a laptop.

The life cycle phases of the laptop showing the largest differences between the BFR and HFFR scenarios are improper WEEE treatment and WEEE-Directive compliant treatment. In both life cycle phases, the BFR scenario has a higher impact. Smaller differences are found in the production phase of the flame-retarded polymers. For the impacts of volatilization in the use phase, emissions during accidental fire, WEEE treatment in a MSWI and WEEE on a landfill, relatively small differences between scenarios are found, with the BFR scenario having a slightly higher impact in these life cycle phases.

While comparison of specific life cycle phases shows that the substitution of BFRs by HFFRs in this case study results in clear environmental benefits, the contribution of FRs to the total environmental impact of the life cycle of a complete laptop is minor.

This study shows that processes which are often ignored in LCA studies can give relevant insights into the environmental performance of a product. It is therefore recommended to broaden the scope and system boundaries of future LCA studies to include unofficial or illegal scenario options (specifically in the end-of-life phase) to provide a more complete description of the full environmental impact of a product's life cycle. Only by including these processes, the influence of the selection of FRs in a product can be quantified in an LCA, providing a relevant contribution to the discussion on the sustainability of electronics.

Acknowledgments All companies which provided details on the production of FRs are kindly acknowledged. This work was financed by the European Commission (the ENFIRO project, FP7-ENV-2008-1226563).

Open Access This article is distributed under the terms of the Creative Commons Attribution 4.0 International License (http:// creativecommons.org/licenses/by/4.0/), which permits unrestricted use, distribution, and reproduction in any medium, provided you give appropriate credit to the original author(s) and the source, provide a link to the Creative Commons license, and indicate if changes were made.

\section{References}

Alaee M, Arias P, Sjodin A, Bergman A (2003) An overview of commercially used brominated flame retardants, their application, their use 
patterns in different countries/regions and possible release, Elsevier. Environ Int 29:683-689

Andersson P, Simonson M, Stripple H (2003) Fire-LCA model: furniture study. SP report 2003: 22. Sweden

Andersson P, Simonson M, Tullin C, Stripple H, Sundqvist JO, Paloposki T (2004) Fire-LCA guidelines. SP report 2004:43. Sweden, ISBN 91-85303-21-6

Andersson P, Simonson M, Rosell L, Blomqvist P, Stripple H (2005) FireLCA model: cable case study II-NHXMH and NHMH cable. SP Swedish National Testing and Research Institute. SP Report 2005: 45

Andrae ASG, Andersen O (2010) Life cycle assessments of consumer electronics - are they consistent? Int J Life Cycle Assess 15:827836

Andrae ASG, Edler T (2015) On global electricity usage of communication technology: trends to 2030. Challenges 6:117-157

Andrae ASG, Vaija MS (2014) To which degree does sector specific standardization make life cycle assessments comparable? - the case of global warming potential of smartphones. Challenges 5:409-429

Andrae ASG, Östermark U, Liu J (2000) Life cycle assessment of a telecommunications exchange. J Electron Manuf 10:147-160

Andrae ASG, Zou G, Liu J (2004) LCA of electronic products. Int J Life Cycle Assess 9:45-52

Andrae ASG, Andersson DR, Liu J (2005) Significance of intermediate production processes in life cycle assessment of electronic products assessed using a generic compact model. J Clean Prod 13:12691279

Andrae ASG, Itsubo N, Yamaguchi H, Inaba A (2008) Life cycle assessment of Japanese high-temperature conductive adhesives. Environ Sci Technol 42:3084-3089

Askham C (2012) REACH and LCA - methodological approaches and challenges. Int J Life Cycle Assess 17:43-57

Askham C, Gade AL, Hanssen OJ (2013) Linking chemical risk information with life cycle assessment in product development. J Clean Prod 51:196-204

Blomqvist P (2005) Emissions from fires. Consequences for human safety and the environment, doctoral thesis, Lund University

Brigden K, Webster J, Labunska I, Santillo D (2007) Toxic chemicals in computers reloaded. Greenpeace Research Laboratories, Technical note $06 / 07$

ChemSec - the International Chemical Secretariat (2010) Brominated flame retardants and PVC - a market overview

Chen D, Hale RC (2010) A global review of polybrominated diphenyl ether flame retardant contamination in birds. Environ Int 36:800 811

Ciroth A, Franze J (2011) LCA of an ecolabeled notebook consideration of social and environmental impacts along the entire life cycle. GreenDeltaTC GmbH

Cobbing M (2008) Toxic Tech-not in our backyard. Uncovering the hidden flows of e-waste. Greenpeace report

Cusack PA (2008) Tin compounds as flame retardants and smoke suppressants. In: Davies AG, Gielen M, Pannell K, Tiekink E (eds) Tin chemistry-fundamentals, frontiers \& applications. Wiley, New York, pp 339-350

D'Silva K, Fernandes A, Rose M (2004) Brominated organic micropollutants - igniting the flame retardant issue. Crit Rev Environ Sci Technol 34:141-207

De Poortere M, Schonbach C, Simonson M (2000) The fire safety of TV set enclosure materials, a survey of European statistics. Fire Mater 24:53-60

De Wit CA (2002) An overview of brominated flame retardants in the environment. Chemosphere 46:583-624

Deng L, Babbitt CW, Williams ED (2011) Economic-balance hybrid LCA extended with uncertainty analysis: case study of a laptop computer. J Clean Prod 19:1198-1206
Destaillats H, Maddalena RL, Singer BC, Hodgson AT, McKone TE (2008) Indoor pollutants emitted by office equipment: a review of reported data and information needs. Atmos Environ 42:1371-1388

Dodbiba G, Takahashi K, Sadaki J, Fujita T (2008) The recycling of plastic wastes from discarded TV sets: comparing energy recovery with mechanical recycling in the context of life cycle assessment. $\mathrm{J}$ Clean Prod 16:458-470

Duan H, Eugster M, Hischier R, Streicher-Porte M, Li J (2009) Life cycle assessment study of a Chinese desktop personal computer. Sci Total Environ 407:1755-1764

EFRA (2010) Keeping fire in check - an introduction to flame retardants used in electrical and electronic devices

Elduque D, Javierre C, Pina C, Martínez E, Jiménez E (2014) Life cycle assessment of a domestic induction hob: electronic boards. J Clean Prod 76:74-84

European Commission (2002) European union risk assessment reportbis(pentabromophenyl) ether

European Commission (2003) Technical guidance document on risk assessment

European Commission (2007) Risk assessment of 2,2',6,6'-tetrabromo-4, $4^{\prime}$-isopropylidene diphenol (tetrabromobisphenol-A)

European Commission (2008a) European Union risk assessment reportdiantimony trioxide

European Commission (2008b) Commission staff working paper accompanying the Proposal for a Directive of the European Parliament and of the Council on waste electrical and electronic equipment (WEEE) (recast) - impact assessment, COM(2008) 810, SEC(2008) 2934

European Commission (2010) Being wise with waste: the EU's approach to waste management. Publications Office of the European Union

Freedonia (2013) World flame retardants - industry study with forecasts for 2016 \& 2021. The Freedonia Group, Study 2987

Gullett BK, Linak WP, Touati A, Wasson SJ, Gatica S, King CJ (2007) Characterization of air emissions and residual ash from open burning of electronic wastes during simulated rudimentary recycling operations. J Mater Cycles Waste Manag 9:69-79

Gunnar Bergendahl C, Lichtenvort K, Johansson G, Zackrisson M, Nyyssönen J (2005) Environmental and economic implications of a shift to halogen-free printed wiring boards. Circuit World 31:26-31

Hamzia R, Londichea H, Bourmada N (2008) Fire-LCA model for environmental decision-making. Chem Eng Res Des 86:1161-1166

Hischier R (2015) Life cycle assessment study of a field emission display television device. Int J Life Cycle Assess 20:61-73

Hischier R, Baudin I (2010) LCA study of a plasma television device. Int J Life Cycle Assess 15:428-438

Huisman J, Van der Maesen M, Eijsbouts RJJ, Wang F, Baldé CP, Wielenga CA (2012) The Dutch WEEE flows. 2011 Dutch ewaste quantification. United Nations University, ISP - SCYCLE

Iji M, Yokoyama S (1997) Recycling of printed wiring boards with mounted electronic components. Circuit World 23:10-15

IVF (2007) Personal computers (desktops and laptops) and computer monitors final report (Task 1-8), IVF Industrial Research and Development Corporation, TREN/D1/40-2005, Lot 3, European Commission DG TREN - Preparatory studies for Eco-design Requirements of EuPs, IVF Report 07004

Kuper J, Hojsik M (2008) Poisoning the poor. Electronic waste in Ghana, Greenpeace report

Lavoie ET, Heine LG, Holder H, Rossi MS, Lee RE, Connor EA, Vrabel MA, Difiore DM, Davies CL (2010) Chemical alternatives assessment: enabling substitution to safer chemicals. Environ Sci Technol 44:9244-9249

Matthews HS, Lave L, MacLean H (2002) Life cycle impact assessment: a challenge for risk analysts. Risk Anal 22:853-860

Nibra-Netherlands Institute for Safety Consumer fire safety (2009) European statistics and potential fire safety measures, report commissioned by the Consumer Council at the Austrian Standards 
Institute and funded by the Austrian Ministry for Labour, Social Affairs and Consumer Protection. version: 431N8032/3.0

Nnorom IC, Osibanjo O (2008) Sound management of brominated flame retarded (BFR) plastics from electronic wastes: State of the art and options in Nigeria. Resour Conserv Recycl 52:1362-1372

Nordbrand S (2009) Out of control. E-waste trade flows from the EU to developing countries. SwedWatch report, EU-project makeITfair

OECD (2004) Series on emission scenario documents, Number 3: emission scenario document on plastics additives. pp 88-92

Perkins DN, Drisse MNB, Nxele T, Sly PD (2014) E-waste: a global hazard. Ann Glob Health 80(4):286-295

Robinson BH (2009) E-waste: an assessment of global production and environmental impacts. Sci Total Environ 408:183-191

Scharnhorst W, Althaus HJ, Classen M, Jolliet O, Hilty LM (2005) The end of life treatment of second generation mobile phone networks: Strategies to reduce the environmental impact. Environ Impact Assess Rev 25:540-566

Sepúlveda A, Schluep M, Renaud FG, Streicher M, Kuehr R, Hagelüken C, Gerecke AC (2010) A review of the environmental fate and effects of hazardous substances released from electrical and electronic equipments during recycling: Examples from China and India. Environ Impact Assess Rev 30:28-41

Shaw S, Blum A, Weber R, Kannan K, Rich D, Lucas D, Koshland CP, Dobraca D, Hanson S, Birnbaum LS (2010) Halogenated flame retardants: do the fire safety benefits justify the risks? Rev Environ Health 25:261-305

Simonson M, Blomqvist P, Boldizar A, Möller K, Rosell L, Tullin C, Stripple H, Sundqvist J (2000) Fire-LCA model: TV case study. SP Swedish National Testing and Research Institute, SP Report 2000: 13
Simonson M, Tullin C, Stripple H (2002) Fire-LCA study of TV sets with $\mathrm{V} 0$ and $\mathrm{HB}$ enclosure material. Chemosphere 46:737-744

Sjölin S (2012) Stena Metall AB, personal communication

Socolof ML, Geibig JR (2006) Evaluating human and ecological impacts of a product life cycle: the complementary roles of life-cycle assessment and risk assessment. Hum Ecol Risk Assess 12:510-527

Van Zelm R, Huijbregts MAJ, Van de Meent D (2009) USES-LCA 2.0: a global nested multi-media fate, exposure and effects model. Int $\mathbf{J}$ Life Cycle Assess 14:282-284

VECAP (2011) Voluntary emissions control action programmeMeasurable achievements - annual progress report

Waaijers SL, Kong D, Hendriks HS, De Wit CA, Cousins IT, Westerink RHS, Leonards PEG, Kraak MHS, Admiraal W, De Voogt P, Parsons JR (2013) Persistence, bioaccumulation and toxicity of halogen-free flame retardants. Rev Environ Contam Toxicol 222:1-71

Wang F (2012) United Nations University, Technical University Delft, The Netherlands, personal communication

Weber R, Kuch B (2003) Relevance of BFRs and thermal conditions on the formation pathways of brominated and brominated-chlorinated dibenzodioxins and dibenzofurans. Environ Int 29:699-710

WEEE-forum (2010) 2009 Key figures. Key figures on quantities of electrical and electronic equipment put on the market, quantities of WEEE collected, and costs related to WEEE management, WEEEforum, European Association of electrical and electronic waste take back systems

Yung WK, Chan HK, Wong DW, So JH, Choi AC, Yue TM (2009) Life cycle assessment of two personal electronic products - a note with respect to the energy-using product directive. Int $\mathrm{J}$ Adv Manuf Technol 42:415-419 